\title{
Allozyme variation and sociogenetic structure of Polistes satan Bequaert 1940 colonies (Hymenoptera, Vespidae)
}

\author{
Jane Cristina Wehren Gaspar, Margarita María López-Uribe and Marco Antônio Del Lama \\ Laboratório de Genética Evolutiva de Himenópteros, Departamento de Genética e Evolução, \\ Universidade Federal de São Carlos, São Carlos, SP, Brazil.
}

\begin{abstract}
We collected 40 colonies of the wasp Polistes satan in November 1993 (Population A = 23 colonies) and October 1995 (Population B = 17 colonies) from the town of Delfinopólis in the Brazilian state of Minas Gerais. Pupae from these nests were used to assess allozyme variation and genetic relatedness among nestmates. Of the 24 gene loci sampled six showed allozyme polymorphism (Est-2, Pgm-1, 6Pgd, Hk-1, Idh and Pep-A) and all loci except Idh were at Hardy-Weinberg equilibrium. Populations $A$ and B showed distinct intra-loci heterozygosities, but similar average heterozygosity over all loci. Significant inter-population differentiation (Fst $=0.051 ; p<0.01$ ) was detected, probably due to genetic drift driven by bottlenecking that occurred due to the first sampling. Mean intra-colony relatedness values between female broods $\left(r_{A}=0,525 \pm 0.063 ; r_{B}=0,456 \pm 0.103\right)$ indicated that $P$. satan has a simple sociogenetic structure where one female takes on most of the reproductive tasks but, eventually, subordinates also reproduce in the colony.
\end{abstract}

Key words: allozymes, gene variation, Polistes satan, relatedness, wasps.

Received: May 10, 2006; Accepted: September 29, 2006.

The evolution of social behavior in colonial organisms is one of the most puzzling questions in evolutionary biology because only one, or relatively few, members of a social colony reproduce. According to Hamilton's principle of inclusive fitness (Hamilton, 1964a, b), this apparent altruistic behavior is explained by the capacity of individual members of a colony to improve their fitness not only by their own reproduction but also by assisting the reproduction of other members of the colony that carry the same genes. Alternatively, Wilson and Hölldobler (2005) have suggested that high relatedness may be more a consequence than a cause of social behavior.

Hamilton's principle states that cooperative behavior is favored only if the ratio between the benefits to the recipient (b) to the costs to the helper (c) exceeds $1 / r$, where $r$ is the relatedness between the helper and the recipient. The costs and benefits of altruistic acts are difficult to measure in highly eusocial insects and, consequently, studies on social evolution generally measure relatedness among nestmates within colonies (Seppa et al., 2002; Tsuchida et al., 2003; Sayama and Takahashi, 2005). Estimates of relat-

Send correspondence to Marco Antônio Del Lama. Laboratório de Genética Evolutiva de Himenópteros, Departamento de Genética e Evolução, Universidade Federal de São Carlos, Rodovia Washington Luis km 235, 13565-905 São Carlos, SP, Brazil. E-mail: dmdl @ power.ufscar.br. edness among nestmates coupled with the levels of polygyny and polyandry indicate the sociogenetic structure of colonies. Knowledge of the sociogenetic structure of primitively eusocial insect colonies helps us understand the evolution of insect sociality.

Vespid wasps (Vespidae) encompass species with behavior which ranges from solitary to highly eusocial and are thus model organisms for the study of the evolution of social behavior in insects. Wasps of the subfamily Polistinae, also known as paper-wasps, have been particularly studied because their primitively eusocial organization helps us understand the conditions and requirements for the evolution of social behavior. The genus Polistes has also been widely studied due to its cosmopolitan distribution, short life cycles and small open-combed nests which allow easy direct observation (Pardi, 1996). The variety of social behavior found among paper-wasp species is also appropriate for studying parameters determining dominance behavior within the colony (West-Eberhard, 1986; Seppa et al., 2002).

Colonies of Polistes wasps can be founded either through the swarming of an existing colony or the independent founding of colonies by a single female or a group of females. When foundation is by several females the dominant one becomes the egg-layer while subordinates take care of the brood and have little chance of reproduction 
(Strassmann, 1996), hence the high reproductive cost to the subordinate females means that related females tend to associate for nest founding. In Polistes wasps, nestmate associations are ensured by kin recognition of cuticular chemicals and philopatry (Dapporto et al., 2004), although kin recognition may not be as widespread as was though and, therefore, errors in nestmate identification lower the intracolony relatedness below the expected 0.75 for full sisters (Gamboa, 2004). The association of non-related females for colony foundation causes strong conflicts regarding reproductive tasks and eventually leads to aggressive interactions between the dominant female and her subordinates. Another aspect that potentially lowers intra-colony relatedness is intraspecific usurpation, which has been reported for some Polistes wasp and especially occurs when a female is unsuccessful in constructing a nest on her own (Makino, 1989).

The wasp Polistes satan Bequaert 1940 is a Neotropical paper wasp which is distributed in southeastern Brazil (Carpenter, 1996) and has abundant nests in dark sheltered places such as buildings. This wasps has a typical tropical colony cycle, with long nesting periods and annual asynchrony but differs from other tropical species in that while in some cases $P$. satan females die during the driest and coldest winter months of June and July they can sometimes form winter aggregates, with colony founding being active during August and September at the end of the cold-dry season and colony foundation through satellite nest formation occuring during the warm-wet season from November to March (Tannure-Nascimento et al., 2005).

In general, female founders (foundresses) of tropical wasp species are morphologically very similar and it is difficult to establish the sociogenetic structure of colonies through direct observation. As a result, there is little information on the colony structure of tropical species (Gamboa, 2004) despite the fact that most Polistes species are indeed restricted to the tropics. Therefore, genetic studies provide a useful tool for accessing information on the social structure of Polistes colonies. We used allozyme markers to estimate the genetic variation of $P$. satan populations and to establish the sociogenetic structure based on the intracolony relatedness of the brood.

During the 1993 and 1995 November to March wet seasons we collected $P$. satan colonies (adults and brood) inside abandoned buildings at a farm near the town of Delfinópolis (20¹0'31" S, 46 51'14" W) in Minas Gerais state in southeastern Brazil. Forty nests in different stages of development were collected, 23 in November 1993 (population A) and 17 in October 1995 (population B). All nests present in the buildings were collected separately in plastic bags, although a few adults escaped during collection. All pupae were removed from the brood cells, sexed and placed individually in glass vials. Samples were kept at $-20{ }^{\circ} \mathrm{C}$ until the analyses were performed.
Proteins were extracted from pupae in a $0.2 \% 2$-mercaptoethanol solution and the samples analyzed using horizontal electrophoresis in $14 \%(\mathrm{w} / \mathrm{v})$ starch gels. The 22 enzyme systems analyzed are shown in Table 1, buffers and reaction mixtures being prepared according to the standard protocols by Harris and Hopkinson (1976).

Genetic variability was estimated as the intra-locus heterozygosity $\left(\mathrm{H}_{\mathrm{i}}=1-\Sigma \mathrm{p}^{2}\right)$ and the mean observed heterozygosity $\left(\mathrm{H}_{\mathrm{obs}}=\Sigma \mathrm{H}_{\mathrm{i}} / \mathrm{n}\right)$ based on the genotypes of the females. A chi-squared $\left(\chi^{2}\right)$ homogeneity test was performed to test for differences between the allelic frequencies in populations A and B. Deviations from Hardy-Weinberg (HW) equilibrium and F-statistics were tested using the Genepop program v3.4 with 1000 iterations of a Markov chain (Raymond and Rousset, 1995). The $\chi^{2}$ values for the F-statistics parameters were estimated following Workman and Niswander (1970) and Nei (1977). Mean intra-colony relatedness was calculated using the Relatedness $4.2 \mathrm{c}$ program (Queller and Goodnight, 1989), with colonies equally weighted and jackknifing over groups. As seven of the nests were composed of males only, the relatedness values between females were estimated based on 33 of the 40 nests examined.

The 22 enzyme systems analyzed were attributed to 29 gene loci. Data from the Ak, Pep-D, Gpi, Ac, and Fum loci were not included in the analysis due to low resolution, with the $A c$ and Fum loci presenting an uncharacterized polymorphism. Six loci (Est-2, Pgm-1, 6Pgd, Hk-1, Idh and Pep-A) were polymorphic at the $95 \%$ level. Estimation of population parameters was based on females only. In Population A, all polymorphic loci presented two alleles, whereas in Population B the Est-2 locus presented only one fixed allele $(F)$ and $P e p-A$ presented three alleles $(F, M$, and $S)$. The Pep-A $S$ allele was rare in population A and was present in only two male wasps, because of which it was not included in the analysis. Mean observed heterozygosities $\left(\mathrm{H}_{\mathrm{obs}}\right)$ were 0.061 for population $\mathrm{A}$ and 0.060 for population $\mathrm{B}$ (Table 2). The genotypes of all 55 males from the 33 colonies analyzed were haploid, indicating the absence of diploid males in our sample.

All loci were at HW equilibrium, except for the Idh locus in population A, which presented a deficit of heterozygotes (Table 2). This deficit was also evident in the endogamy coefficient $\left(\mathrm{F}_{\mathrm{IS}}\right.$ ), which was significant for $I d h$ in population A (Table 3 ). The homogeneity test revealed that allelic frequencies for all loci except 6-Pgd were significantly different between the two populations (Table 2). The $\mathrm{F}_{\mathrm{ST}}$ values confirmed the differences in the distribution of Est-2, Idh, Hk and Pep-A genotypes between populations A and $\mathrm{B}$ (Table 3), which were therefore treated as different genetic demes.

Total brood (males plus females) mean within-colony relatedness for population A was $0.384 \pm$ a standard deviation of 0.069 while for population B it was $0.405 \pm 0.088$. When females only were considered the female brood relat- 
Table 1 - The 22 enzyme systems analyzed.

\begin{tabular}{|c|c|c|c|}
\hline \multirow{2}{*}{$\begin{array}{l}\text { Enzyme } \\
\text { (Enzyme Commission (EC) number) }\end{array}$} & \multicolumn{3}{|c|}{ Abbreviations } \\
\hline & Enzyme & locus & Buffer $^{\dagger}$ \\
\hline Aconitase $(4.2 .1 .3)$ & $\mathrm{AC}$ & $A c$ & $\mathrm{TC}$ \\
\hline Alcohol dehydrogenase (1 1.1 .1 .1$)$ & $\mathrm{ADH}$ & Adh & $\mathrm{TC}$ \\
\hline Adenylate kinase (2 .7 .1.20) & $\mathrm{AK}$ & $A k$ & TC8 \\
\hline Diaphorase (1 .6 .5.2.) & DIA & Dia & $\mathrm{TC}$ \\
\hline Esterase (3.1.1.1) & EST & Est-2 & $\mathrm{TC}$ \\
\hline Fumarase (4 .2.1.2) & FUM & Fum & $\mathrm{TC}$ \\
\hline Glucose-6-phosphate dehydrogenase (1.1.1.49) & G6PDH & $\mathrm{G} 6 p d h$ & $\mathrm{TC}$ \\
\hline Glucose phosphate isomerase (5 5.3 .1 .9$)$ & GPI & $G p i$ & TC8 \\
\hline Glutamic oxaloacetic transaminase (2.6.1.1) & GOT & Got & $\mathrm{TC}$ \\
\hline$\alpha$-Glycerophosphate dehydrogenase (1.1.1.8) & GPDH & $G p d h$ & $\mathrm{TC}$ \\
\hline Hexokinase (2 .7 .1 .1$)$ & HK & $H k-1$ & TEMM \\
\hline$\beta$-Hydroxybutyrate dehydrogenase (1 1.1.1.30) & $\mathrm{HBDH}$ & $H b d h$ & $\mathrm{TC}$ \\
\hline Isocitrate dehydrogenase (1 1.1 .1 .42$)$ & IDH & $I d h$ & $\mathrm{TC}$ \\
\hline Leucine aminopeptidase (3 .4.11 .1) & LAP & Lap & TTCB \\
\hline Malate dehydrogenase (1 1.1 .1 .37$)$ & $\mathrm{MDH}$ & $M d h$ & $\mathrm{TC}$ \\
\hline Malic enzyme (1 1.1 .1 .40$)$ & ME & $\mathrm{Me}$ & $\mathrm{TC}$ \\
\hline Phosphoglucomutase (2 27.5 .1$)$ & PGM & Pgm-1 & TEMM \\
\hline Peptidase A, B and D $\left(3.4 .^{*}\right)^{\ddagger}$ & PEP A, B, D & $\operatorname{Pep} A, B, D$ & TCB \\
\hline 6-phosphogluconate dehydrogenase (1 1.1 .1 .46$)$ & 6-PGD & $6 P g d$ & $\mathrm{TC}$ \\
\hline Sorbitol dehydrogenase (1 .1 .1 .14) & SORDH & Sordh & $\mathrm{TC}$ \\
\hline Superoxide dismutase (1.15.11)) & SOD & Sod & TCB \\
\hline Trehalase (3.2.1.28) & TRE & Tre & TC8 \\
\hline
\end{tabular}

${ }^{\dagger} \mathrm{TC}=$ Tris citric acid, $\mathrm{pH} 7.5$; TC8 = Tris citric acid, $\mathrm{pH} 8.0$; TEMM = Tris EDTA maleic anhydride magnesium $\mathrm{pH}$ 7.4; and TTCB = Tris citric acid borate, $\mathrm{pH}$ 8.0-8.3. Buffers and reaction mixtures were prepared according to the standard protocols described by Harris and Hopkinson (1976).

Peptidase: A = leucine-alanine; $\mathrm{B}=$ leucine-glycine-glycine; $\mathrm{D}=$ leucine-proline.

Table 2 - Allele frequencies (p); intra-locus heterozygosity $\left(\mathrm{H}_{\mathrm{i}}\right)$; Hardy-Weinberg equilibrium chi-squared $\left(\chi_{\text {HW }}^{2}\right)$ and homogeneity test $\left(\chi_{\text {hom }}^{2}\right)$ values and mean observed heterozygosity $\left(\mathrm{H}_{\mathrm{obs}}\right)$ over 24 enzyme loci in two Polistes satan populations.

\begin{tabular}{|c|c|c|c|c|c|c|c|c|}
\hline \multirow[t]{2}{*}{ Locus } & \multirow[t]{2}{*}{ Allele } & \multicolumn{3}{|c|}{ Population A } & \multicolumn{4}{|c|}{ Population B } \\
\hline & & $\mathrm{p}$ & $\mathrm{H}_{\mathrm{i}}$ & $\chi_{\mathrm{hw}}^{2}$ & $\mathrm{p}$ & $\mathrm{H}_{\mathrm{i}}$ & $\chi_{\mathrm{hw}}^{2}$ & $\chi_{\text {hom }}^{2}$ \\
\hline \multirow[t]{2}{*}{ Est-2 } & $F$ & 0.872 & & & 1.000 & & & \\
\hline & $S$ & 0.128 & 0.223 & 0.494 & - & 0 & - & $17.72 * *$ \\
\hline \multirow[t]{2}{*}{ Pgm-1 } & $F$ & 0.885 & & & 0.809 & & & \\
\hline & $S$ & 0.115 & 0.204 & 0.343 & 0.192 & 0.311 & 0.498 & 2.38 \\
\hline \multirow[t]{2}{*}{ 6-Pgd } & $F$ & 0.784 & & & 0.862 & & & \\
\hline & S & 0.216 & 0.339 & 0.107 & 0.138 & 0.238 & 0.009 & 0.66 \\
\hline \multirow[t]{2}{*}{$H k-1$} & $F$ & 0.138 & & & 0.021 & & & \\
\hline & $S$ & 0.862 & 0.238 & 0.619 & 0.979 & 0.041 & 0 & $10.21 * *$ \\
\hline \multirow[t]{2}{*}{$I d h$} & $F$ & 0.353 & & & 0.489 & & & \\
\hline & $S$ & 0.647 & 0.457 & $4.515^{*}$ & 0.511 & 0.500 & 0.213 & 3.60 \\
\hline \multirow[t]{3}{*}{ Pep- $A$} & $F$ & 0.005 & & & 0.075 & & & \\
\hline & $M$ & 0.995 & & & 0.798 & & & \\
\hline & $S$ & - & 0.009 & 0 & 0.128 & 0.345 & 0.003 & $24.73 * *$ \\
\hline $\mathrm{H}_{\text {obs }}$ & & & 0.061 & & & 0.060 & & \\
\hline
\end{tabular}


Table 3 - F-statistics $\left(\mathrm{F}_{\mathrm{is}}, \mathrm{F}_{\mathrm{st}}\right.$, and $\mathrm{F}_{\mathrm{it}}$ ) and chi-squared $\left(\chi^{2}\right)$ values for each enzyme locus at the $95 \%(*)$ and $99 \%(* *)$ level of significance for the specified degrees of freedom (DF).

\begin{tabular}{lcccccc}
\hline Locus & Df & $\mathrm{F}_{\mathrm{IS}}$ & $\chi^{2}$ & $\mathrm{~F}_{\mathrm{ST}}$ & $\chi^{2}$ & $\mathrm{~F}_{\text {IT }}$ \\
\hline Est-2 & 1 & -0.141 & 3.10 & 0.089 & $27.92^{*}$ & -0.039 \\
6-Pgd & 1 & -0.075 & 0.89 & 0.012 & 3.77 & -0.062 \\
Idh & 1 & 0.174 & $4.72^{*}$ & 0.029 & $9.14^{*}$ & 0.198 \\
$H k$ & 1 & -0.144 & 3.22 & 0.065 & $20.12^{* *}$ & -0.070 \\
Pgm-1 & 1 & -0.002 & 0 & 0.017 & 5.304 & 0.015 \\
Pep-A & 2 & 0.009 & 0.01 & 0.210 & $131.10^{* *}$ & 0.217 \\
All & 7 & -0.075 & 11.94 & 0.051 & $197.36^{* *}$ & 0.059 \\
\hline
\end{tabular}

edness increased to $0.525 \pm 0.063$ for population $\mathrm{A}$ and $0.456 \pm 0.103$ for population $\mathrm{B}$, such variation in relatedness being expected when only females are analyzed because male haplodiploidy does not increase sister-brother relatedness.

The fact that there was no deviation from HW equilibrium for most of the loci suggests that the populations were at genetic equilibrium. However, the F-statistics values point to genetic changes between populations A and B over the two-year sampling period. The loss of the Est-2 $S$ allele and the drastic reduction of the $H k-1 F$ allele suggest that population $\mathrm{B}$ underwent a reduction in population size and lost variation through genetic drift. Recent studies have shown the existence of diploid males and triploid females in Polistes populations that have experienced genetic bottlenecks (Tsuchida et al., 2002; Liebert et al., 2004; Tsuchida et al., 2004). However, our results show that even if population B resulted from a bottleneck, all the males analyzed were haploids while all females were diploids. The probability of one sampled diploid male being heterozygous for at least one polymorphic locus $\left(P_{h e t}\right)$ was $83 \%$ for both populations, indicating that the genetic marker used had a high probability of detecting a diploid male if present in our samples.

The fixation of the Est-2 $F$ allele and the increase of the Pep- $A S$ allele in population B is probably the result of genetic drift associated to the reduction in population size. In population $\mathrm{A}$, the presence of the Pep- $A S$ allele in two males but its absence in all females suggests that migration occurred before the 1993 sampling period. Female Polistes wasps show strong phylopatric behavior and although the migration of solitary females is rare it may sometimes occur (Dapporto et al., 2004), explaining the first detection of the Pep- $A S$ allele.

Although the intra-locus heterozygosity values $\left(\mathrm{H}_{\mathrm{i}}\right)$ varied widely and $\chi^{2}$ homogeneity test and $\mathrm{F}_{\text {st }}$ values (Table 3) demonstrated that the allelic frequencies between the populations were significantly different the mean observed heterozygosities found were very similar (Table 2), indicating a rapid recovery of genetic variation after the bottlenecking.
The mean heterozygosity values found by us were similar to those described for other Hymenopteran species. Lester and Selander (1979) described heterozygosity values for Hymenoptera ranging from 0.033 to 0.084 while Graur (1985) reported a mean heterozygosity of $0.044 \pm 0.006$ for 13 wasp species, although this dropped to $0.031 \pm 0.006$ when only primitively eusocial wasps were considered. In the study by Metcalf et al. (1984) the genetic variability $\left(\mathrm{H}_{\mathrm{obs}}\right)$ was 0.073 for Polistes metricus and 0.065 for Polistes fuscatus, supporting the mean observed heterozygosity estimated for six Polistes species by Owen (1985). Although Berkelhamer (1983) proposed that primitively eusocial Hymenoptera species are less variable than either solitary or advanced social species, our findings show high genetic variation in the primitively eusocial paper-wasp $P$. satan.

Mean intra-colony relatedness among female offspring was lower than the expected 0.75 for full sisters $\left(r_{A}=0.525 ; r_{B}=0.456\right)$. As a single mate seems to be the rule among Polistes females (Strassmann, 2001), these values of relatedness indicate that more than one female in a colony is able to reproduce. Thus, inseminated subordinate $P$. satan females take over some reproductive tasks, which is easier in a colony structure based on satellite nests (Strassmann, 1981). The population B male relatedness coefficient $\left(\mathrm{r}_{\mathrm{M}-\mathrm{B}}=0.364\right)$ also supports the hypothesis that subordinates can reproduce. When our results are compared with those of similar allozyme marker studies it can be seen that the relatedness values for $P$. satan nestmates are higher than those for other tropical species such as $P$. versicolor $(0.371 \pm 0.084)$ and $P$. canadensis (0.339 \pm 0.097) (Strassmann et al., 1989).

Hymenoptera species display significantly lower levels of electrophoretic variation than most other insects, possibly due to, among other factors, the exposure of deleterious genes in the haploid sex, the presence of eusociality and small effective population size resulting in a reduction of polymorphism (Graur, 1985). However, our results indicate that allozyme markers can be useful tools for estimating relatedness in some Hymenoptera despite having low variability and being less variable than other markers such as microsatellites. Tsuchida et al. (2003) estimated related- 
ness for $P$. chinensis antennalis using allozymes and microsatellites and found no statistical difference between relatedness values.

Our results have implications both at the population and colony level. At the population level we found a loss of alleles which was probably associated with a reduction in the population size of $P$. satan due to our first sampling. However, the mean observed heterozygosities between the two populations were the same, indicating that population $\mathrm{B}$ rapidly recovered from the bottleneck. At the colony level, the relatedness values among nestmates in $P$. satan colonies indicate that although one female (mated once only) plays the main reproductive role in the colony, subordinate females also reproduce. Since direct observations are difficult due to the morphological similarity among nestmates in a colony these genetic data are very valuable for understanding the sociogenetic structure of tropical species of Polistes wasps.

\section{Acknowledgments}

We thank Maria Ivone Casale for her technical assistance and the Brazilian agencies CNPq and CAPES for fellowships and financial support.

\section{References}

Belkelhamer RC (1983) Intraspecific genetic variation and haplodiploidy, eusociality, and polygyny in the Hymenoptera. Evolution 37:540-545.

Carpenter JM (1996) Distributional checklist of species of the genus Polistes (Hymenoptera, Vespidae, Polistinae, Polistini). Am Museum Novitates 3188:URI: http://hdl.handle.net/ 2246/3649.

Dapporto L, Pansolli C and Turillazzi S (2004) Hibernation clustering and its consequences for associative nest foundation in Polistes dominulus (Hymenoptera, Vespidae). Behav Ecol Sociobiol 56:315-321.

Gamboa GJ (2004) Kin recognition in social wasps. Ann Zool Fennici 41:789-808.

Graur D (1985) Gene diversity in Hymenoptera. Evolution 39:190-199.

Hamilton WD (1964a) The genetical evolution of social behaviour. I. J Theor Biol 7:1-16.

Hamilton WD (1964b) The genetical evolution of social behaviour. II. J Theor Biol 7:17-52.

Harris H and Hopkinson DA (1976) Handbook of Enzyme Electrophoresis in Human Genetics. North-Holland Publishing, Amsterdam.

Lester LJ and Selander RK (1979) Genetic relatedness of haplodiploid insects. Genetics 92:1329-1345.

Liebert AE, Johnson RN, Switz GT and Starks PT (2004) Triploid females and diploid males: Unreported phenomena in Polistes wasps? Insectes Soc 51:205-211.

Makino S (1989) Usurpation and nest rebuilding in Polistes riparius: Two ways to reproduce after the loss of the original nest (Hymenoptera, Vespidae). Insectes Soc 36:116-128.
Metcalf RA, Marlin JC and Whitt GS (1984) Genetics of speciation within the Polistes fuscatus species complex. J Hered 75:115-120.

Nei M (1977) F-statistics and analysis of gene diversity in subdivided populations. Ann Hum Genet 41:225-233.

Owen RE (1985) Difficulties with the interpretation of patterns of genetic variation in the eusocial Hymenoptera. Evolution 39:201-205.

Pardi L (1996) Polistes: Analysis of a society. In: Turillazzi S and West-Eberhard MJ (eds) Natural History and Evolution of Paper-Wasps. Oxford University Press, New York, pp 1-17.

Queller DC and Goodnight KF (1989) Estimating relatedness using genetic markers. Evolution 43:258-275.

Raymond M and Rousset F (1995) Genepop (version 3.3): Population genetics software for exact tests and ecumenicism. J Hered 86:248-249.

Sayama K and Takahashi J (2005) Mating structure and genetic relatedness among gynes in the primitively eusocial wasp Polistes snelleni (Hymenoptera, Vespidae). Entomol Sci 8:27-31.

Seppa P, Queller DC and Strassmann JE (2002) Reproduction in foundress associations of the social wasp, Polistes carolina: Conventions, competition, and skew. Behav Ecol 13:531542.

Strassmann JE (1981) Evolutionary implications of early male and satellite nest production in Polistes exclamans colony cycles. Behav Ecol Sociobiol 8:55-64.

Strassmann JE (1996) Selective altruism towards closer over more distant relatives in colonies of the primitively eusocial wasp, Polistes. In: Turillazzi S and West-Eberhard MJ (eds) Natural History and Evolution of Paper-Wasps. Oxford University Press, New York, pp 190-201.

Strassmann JE (2001) The rarity of multiple mating by females in the social Hymenoptera. Insectes Soc 48:1-13.

Strassmann JE, Hughes CR, Queller DC, Turillazzi S, Cervo R, Davis SK and Goodnight KF (1989) Genetic relatedness in primitively eusocial wasps. Nature 342:268-270.

Tannure-Nascimento IC, Nascimento FS and Zucchi R (2005) Size and colony cycle in Polistes satan, a Neotropical paper wasp (Hymenoptera, Vespidae). Ethol Ecol Evol 17:105119.

Tsuchida K, Nagata N and Kojima J (2002) Diploid males and sex determination in a paper wasp, Polistes chinensis antennalis (Hymenoptera, Vespidae). Insectes Soc 49:120-124.

Tsuchida K, Saigo T, Nagata N, Tsujita S, Takeuchi K and Miyano S (2003) Queen-worker conflicts over male production and sex allocation in a primitively eusocial wasp. Evolution 57:2365-2373.

Tsuchida K, Saigo T, Tsujita S and Takeuchi K (2004) Early male production is not linked to a reproductive strategy in the Japanese paper wasp, Polistes chinensis antennalis (Hymenoptera, Vespidae). J Ethol 22:119-121.

West-Eberhard MJ (1986) Dominance relations in Polistes canadensis (L.), a tropical social wasp. Monitore Zool Ital 20:263-281

Wilson EO and Hölldobler B (2005) Eusociality: Origin and consequences. Proc Natl Acad Sci 20:13367-13371.

Workman PL and Niswander JD (1970) Population studies on southwestern Indian tribes II. Local genetic differentiation in The Papago. Am J Hum Genet 22:24-29.

Associate Editor: João S. Morgante 